\title{
The Effect of Poplar PsnGS1.2 Overexpression on Growth, Secondary Cell Wall, and Fiber Characteristics in Tobacco
}

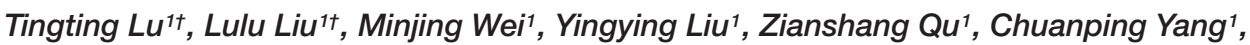 \\ Hairong Wei ${ }^{2 *}$ and Zhigang Wei ${ }^{1 *}$ \\ ' State Key Laboratory of Tree Genetics and Breeding, Northeast Forestry University, Harbin, China, ${ }^{2}$ School of Forest \\ Resources and Environmental Science, Michigan Technological University, Houghton, MI, United States
}

\section{OPEN ACCESS}

Edited by:

Paulo Arruda

Universidade Estadual de Campinas,

Brazil

Reviewed by:

Nobutaka Mitsuda,

National Institute of Advanced

Industrial Science and Technology,

Japan

Cristina Cruz

Universidade de Lisboa, Portugal

*Correspondence:

Hairong We

hairong@mtu.edu

Zhigang Wei

zhigangwei@nefu.edu.cn

tThese authors have contributed equally to this work.

Specialty section: This article was submitted to

Plant Biotechnology,

a section of the journal

Frontiers in Plant Science

Received: 06 June 2017 Accepted: 03 January 2018 Published: 19 January 2018

Citation:

Lu T, Liu L, Wei M, Liu Y, Qu Z, Yang C, Wei H and Wei $Z$ (2018) The

Effect of Poplar PsnGS1.2

Overexpression on Growth, Secondary Cell Wall, and Fiber

Characteristics in Tobacco.

Front. Plant Sci. 9:9.

doi: 10.3389/fpls.2018.00009
The glutamine synthetase (GS1) is a key enzyme that catalyzes the reaction of glutamate and ammonia to produce glutamine in the nitrogen $(\mathrm{N})$ metabolism. Previous studies on GS1s in several plant species suggest that overexpression of GS1s can enhance N utilization, accelerate plant vegetative growth, and change wood formation. In this study, we isolated a GS1 gene, termed PsnGS1.2, from Populus simonii $\times$ Populus nigra. This gene was expressed at a higher level in roots, and relatively lower but detectable levels in xylem, leaves and phloem of $P$. simonii $\times P$. nigra. The protein encoded by PsnGS1.2 is primarily located in the cytoplasm. Overexpression of PsnGS1.2 in tobacco led to the increased GS1 activity and IAA content, the augmented N assimilation, and the enlarged leaves with altered anatomical structures. These changes presumably promoted photosynthetic, growth, and biomass productivity. It was noteworthy that the secondary cell walls and fiber characteristics changed remarkably in PsnGS1.2 transgenic tobacco. These changes aligned well with the altered expression levels of the genes involved in fiber development, secondary cell wall component biosynthesis, IAA biosynthesis, amino acid transport, and starch breakdown. Taken together, the results from our study suggest that catalytic functions of PsnGS1.2 on N assimilation and metabolism in transgenic tobacco had significant effects on vegetative growth, leaf development, and secondary cell wall formation and properties through acceleration of photosynthesis and IAA biosynthesis, and redirection of carbon flux to synthesis of more cellulose and hemicellulose.

Keywords: poplar, PsnGS1.2, overexpression, growth, secondary cell wall, fiber, tobacco

\section{INTRODUCTION}

Plants need to absorb inorganic nitrogen $(\mathrm{N})$ in the form of ammonium $\left(\mathrm{NH}_{4}{ }^{+}\right)$or nitrate $\left(\mathrm{NO}_{3}{ }^{-}\right)$ from soil to maintain their regular or accelerated growth and development (Jackson et al., 2008). Most $\mathrm{NO}_{3}{ }^{-}$molecules are transported to leaves where they are reduced to $\mathrm{NH}_{4}{ }^{+}$for incorporation into organic $\mathrm{N}$ compounds (Black et al., 2002). The $\mathrm{NH}_{4}{ }^{+}$is first assimilated into $\gamma$-ketoglutarate to form glutamate (Glu), which is then converted to glutamine (Gln) by incorporating the other $\mathrm{NH}^{+}{ }^{+}$in the presence of Gln Synthetase (GS) (Tobin and Yamaya, 2001). Since Glu and Gln 
are primary precursors for synthesizing organic $\mathrm{N}$ compounds in plants, GS is considered to be a key regulator in the upstream of pathway in which various $\mathrm{N}$ compounds are synthesized and mobilized (Miflin and Habash, 2002). There are two types of GS isoforms that have distinct roles in plants, one is the cytoplasmic GS1 type and the other is the choroplastic/plastid GS2 type (Hirel et al., 1984; Dubois et al., 1996; Wang et al., 2015). The GS1 usually assimilates $\mathrm{NH}_{4}{ }^{+}$from soil or non-photosynthetic tissues (Ishiyama et al., 2004a), whereas the GS2 mainly acts in the reassimilation of $\mathrm{NH}_{4}{ }^{+}$derived from $\mathrm{NO}_{3}{ }^{-}$reduction and photorespiration in photosynthetic tissues (Migge et al., 2000; Miflin and Habash, 2002; Betti et al., 2014). Over the past decade, numerous studies have been conducted to analyze the functions of GS1s in plant growth and development. The results have indicated that GS1s play pivotal roles during $\mathrm{N}$ metabolism for vegetative growth, photosynthesis, earlier flowering, and seed development in herbaceous plants (Hirel et al., 1992; Vincent et al., 1997; Fuentes et al., 2001; Oliveira et al., 2002; Man et al., 2005; Martin et al., 2006; Seger et al., 2009). In the woody plants, the GS1s have been reported to play principal roles in growth, and development (including wood formation) through assimilation of exterior $\mathrm{N}$ and promotion of $\mathrm{N}$ recycling processes and closely linked ones (Rennenberg et al., 2010; Coleman et al., 2012). Nevertheless, some studies reported the overexpression of GS1s yields no observable alternation of phenotype traits or enhanced $\mathrm{N}$ assimilation (Ortega et al., 2001; Suarez et al., 2003). Since not all GS1s are regulated in the same manner and located in the same type of cells or organs (Ishiyama et al., 2004b; Martin et al., 2006; Bernard et al., 2008; Castro-Rodriguez et al., 2011), GS1s exhibit different functions in $\mathrm{N}$ assimilation and metabolism in some transgenic plants (Ishiyama et al., 2004b; Martin et al., 2006; Lothier et al., 2011). These earlier studies suggest that GS1s are worth studying and characterizing to benefit humans.

Forest trees grow on infertile land where $\mathrm{N}$ deficiency is a critical constraint for their growth and development, it is thus more important and imperative to characterize tree GS1s for genetic breeding to enhance $\mathrm{N}$ utilization. Poplar is an economically important woody species because of its high growth potential, and variety of uses in industry, such as pulping, papermaking, and biofuel. Although it has been reported that poplar GS1 family includes up to six genes (Castro-Rodriguez et al., 2011), the well-defined roles of any GS1s in poplar have not been identified up to now. In this study, we isolated a full-length cDNA of PsnGS1.2 from Populus simonii $\times$ Populus nigra, and investigated its functions through overexpression of it in tobacco. Based on previous studies on other GS1s, we hypothesized that the poplar GS1 we isolated may directly and indirectly affect plant performance through accelerating the absorption of $\mathrm{N}$ and conversion of inorganic into organic nitrogen, and at same time interacting with plant hormonal balance. To test this hypothesis, we first characterized this GS1 gene in tobacco. The results explicitly showed that overexpression of the PsnGS1.2 led to altered $\mathrm{N}$ assimilation and metabolism, increased IAA content, accelerated vegetative growth, changed leaf morphology, and altered secondary cell walls and fiber characteristics in transgenic tobacco. Our results suggest that PsnGS1.2 can be used to create genetically ameliorated plants with significantly augmented biomass production and altered secondary cell walls and fiber characteristics.

\section{MATERIALS AND METHODS}

\section{Plant Materials}

One-year-old Populous simonii $\times$ Populus nigra trees were propagated and planted in a mixture of turfy peat and sand $(2: 1 \mathrm{v} / \mathrm{v})$ in the greenhouse. The primary shoot leaves, transition leaves, secondary leaves, primary xylem, transition xylem, secondary xylem, primary phloem, transition phloem, secondary phloem and roots were collected and immediately frozen in liquid Nitrogen and stored at $-80^{\circ} \mathrm{C}$. The RNA was isolated according to a previously published method (Liao et al., 2004) and later treated with DNase I (Qiagen) to remove genomic DNA (Kolosova et al., 2004).

\section{Cloning PsnGS1.2 from $P$. simonii $x$ $P$. nigra}

Five microgram total RNA were used for the synthesizing cDNAs using SuperScript II Reverse Transcriptase (Invitrogen). The full PsnGS1.2 cDNA was amplified from $P$. simonii $\times$ P. nigra with gene-specific primers (Supplementary Table S1). The PCR product was cloned into pMD18-T vector (TaKaRa), and then transformed into Escherichia coli cells $(\mathrm{DH} 5 \alpha)$ for validation by Sanger sequencing.

\section{Sequence Comparisons and Phylogenetic Analysis}

BLASTX and BLASTP ${ }^{1}$ were used to analyze the sequence similarity of the cDNA and deduced protein of GS1s, respectively. The conserved domains of GS1s were searched by CDD algorithms ${ }^{1}$. Multiple sequence alignment was carried on using ClustalW2 ${ }^{2}$ with default setting. PsnGS1.2 homologous gene sequences from Chlamydomonas reinhardtii (CrGS1.230784960), Zea mays (ZmGS1.2a-30991251), Arabidopsis thaliana (AtGS1.2a-19668213), Oryza sativa (OsGS1.233138580), Morchella esculenta (MeGS1.2c-32327725), Populus trichocarpa (PtrGS1.2a-27031680 and PtrGS1.2b-27016370), Eucalyptus globulus (EgGS1.2-32071611), and Salix purpurea (SpGS1.2-31427432) were retrieved from Phytozome Database ${ }^{3}$ using TBLASTN with the PsnGS1.2 sequence being used as the query. A total of 70 putative GS1 protein sequences from 44 plant species (Supplementary File) were aligned using ClustalW2, and the resulting sequences were used to construct a phylogenetic tree by the neighbor-joining method in MEGA 5.0 software, with 1,000 replicates for bootstrap analysis, and a 50\% cutoff value.

\section{Subcellular Localization}

The full-length coding region of PsnGS1.2 without termination codon was amplified using specific primers (Supplementary

\footnotetext{
${ }^{1}$ http://ncbi.nlm.nih.gov

${ }^{2}$ http://www.ebi.ac.uk/Tools/msa/clustalw2/

${ }^{3}$ http://www.phytozome.net/
} 
Table S2) and then fused to the N-terminal of GFP driven by CaMV 35S promoter in pGWB5 vector. The 35S-PsnGS1.2-GFP fusion construct was delivered into onion epidermal cells via particle bombardment (GJ-1000). The GFP fluorescent images were photographed with confocal microscopy (Leica TCS SP5) at $24 \mathrm{~h}$ after bombardment.

\section{Transformation of Nicotiana tabacum}

The PsnGS1.2 was amplified with specific primers (Supplementary Table S3), and then inserted into the pROKII vector at the position immediately downstream of CaMV 35 S promoter. The pROKII-PsnGS1.2 was first transferred into Agrobacterium tumefaciens EHA105 using the freezethaw method. Tobacco plants (Nicotiana tabacum) were then transformed as described previously (Maiti et al., 1993). Transgenic tobacco lines were selected on MS medium containing $250 \mu \mathrm{g} / \mathrm{ml}$ kanamycin and $500 \mu \mathrm{g} / \mathrm{ml}$ carbenicillin. The T1 seeds from self-pollinated plants were germinated on MS medium with kanamycin $(25 \mathrm{mg} / \mathrm{L})$ to produce $\mathrm{T} 1$ generation transgenic lines. We repeated this process to obtain the T2 generation seeds. The genomic DNA of T2 seedlings was amplified by regular PCR using the PROKII sequencing primers listed in Supplementary Table S3 to verify whether PsnGS1.2 was integrated into tobacco genome. All tested PsnGS1.2 transgenic lines and wild-type (WT) were grown in the greenhouse and subsequently used for characterization.

The plastichron index (PI) method was used to determine tobacco growth phases. The first leaf larger than $5 \mathrm{~cm}$ was named PI0. Then the leaf immediately below PI0 was defined as PI1. Stem segments between PI5 and PI8 were used for breaking force, secondary cell wall thickness, cell wall chemical composition, and gene expression analyses. Leaves of PI3, PI4, and PI5 were measured for leaf lengths and widths, PsnGS1.2 transcript abundance, chlorophyll contents, biochemical and physiological parameters. Leaf samples for biochemical analyses were obtained from central regions of leaves by using a cork borer (4-mm diameter). Disks prepared from each transgenic line or WT were thoroughly mixed. Samples were weighed, frozen in liquid nitrogen and stored at $-80^{\circ} \mathrm{C}$.

\section{Gene Expression Analysis}

Five microgram total RNA from multiple tissues of $P$. simonii $\times P$. nigra and tobacco plants were used for synthesing cDNA, respectively. Samples of cDNA were run in triplicate with the SYBR premix ExTaq kit (TaKaRa) and an Applied Biosystems 7500 Real-Time PCR System to determine the critical threshold (Ct). The PsnGS1.2 expression levels in poplar were detected by the real-time quantitative PCR (qRT-PCR), and the primers used for qRT-PCR of PsnGS1.2 and reference gene, PsnACTIN1, are listed in Supplementary Table S4.

The expression levels of PsnGS1.2 in tobacco lines were determined by reverse transcription (RT)-PCR using NtACTIN2 as an internal reference. All the primers used are shown in Supplementary Table S4.

Analysis of expression levels of genes involved in cell expansion and elongation (ExpansinA, ExpansinB, TIP1;3, TIP1;4, XTH5, and XTH8) (Aspeborg et al., 2005;
Hacke et al., 2010), programmed cell death (XSP1, XCP2, SCPL45, and SCPL49) (Plavcova et al., 2013), and cellulose (CesA4, CesA7, and CesA8) (Appenzeller et al., 2004), hemicellulose (FRA8, IRX9, and IRX10) (Wu et al., 2010) and lignin biosynthesis gens (PAL1, PAL4, CAD14, CAD19, 4CL1, 4CL2, HCT, and CCoAOMT1) (Raes et al., 2003), IAA biosynthesis gene (ASA1) (Stepanova et al., 2005, 2008), membrane amino acid transporter gene (AAP11) (Couturier et al., 2010), and the $\beta$-amylase gene (AMY1) (Castro-Rodriguez et al., 2016) in tobacco were performed using gene-specific primers (Supplementary Table S5). The primers of NtACTIN2, used as an internal control, were listed in Supplementary Table S4. Quantification of gene expression relative to PsnACTIN1 or NtACTIN2 was calculated using the delta-delta CT method (Livak and Schmittgen, 2001).

\section{Phonotype Trait Measurement}

The heights and stem diameters $(3 \mathrm{~cm}$ above the root collar) were measured for each plant. The fresh weights were determined immediately after the whole plants were harvested. Then, the materials were placed in an oven, heated for $10 \mathrm{~min}$ at $100^{\circ} \mathrm{C}$, and then heated at $75^{\circ} \mathrm{C}$ until the weights did not change. The final unchanged weights were recorded as dry weights.

\section{Biochemical Analysis}

For assessment of total GS enzyme activities, the samples were respectively ground on ice with extraction buffer consisting of $70 \mathrm{mM}$ MOPS (pH 6.8), $10 \mathrm{mM} \mathrm{MgSO}_{4}, 2 \mathrm{mM}$ dithiothreitol, $5 \mathrm{mM}$ glutamate, $0.1 \%(\mathrm{v} / \mathrm{v})$ Triton $\mathrm{X}-100$ and $10 \%(\mathrm{v} / \mathrm{v})$ ethanediol. The final $\mathrm{pH}$ of extraction solution was 7.5-8.5. The homogenates were centrifuged at $4^{\circ} \mathrm{C}, 12,000 \mathrm{~g}$ for $30 \mathrm{~min}$, the supernatant was analyzed for total GS activities. Total GS activities were measured in a preincubated assay buffer $\left(37^{\circ} \mathrm{C}\right)$ consisting of $70 \mathrm{mM}$ MOPS ( $\mathrm{pH} 7.6$ ), $100 \mathrm{mM}$ glutamate, $50 \mathrm{mM} \mathrm{MgSO}_{4}, 15 \mathrm{mM} \mathrm{NH} 2 \mathrm{OH}$, and $15 \mathrm{mM}$ ATP. The reaction was terminated after $30 \mathrm{~min}$ at $37^{\circ} \mathrm{C}$ by adding acidic $\mathrm{FeCl}_{3}$ solution $(370 \mathrm{mM} \mathrm{FeCl}, 670 \mathrm{mM} \mathrm{HCl}, 200 \mathrm{mM}$ trichloroacetic acid) (Lynch and Barbano, 1999). The reaction was set for $5 \mathrm{~min}$ to allow colors to develop, and then centrifuged at $4,000 \mathrm{~g}$ at room temperature for $10 \mathrm{~min}$, and the supernatant was transferred into a new tube. The amount of formed $\gamma$-glutamyl hydroxamate $(\gamma$-GHA) was determined with spectrophotometer at $540 \mathrm{~nm}$ by reference to the standard curve of $\gamma$-GHA.

For soluble protein analysis, each sample was homogenized by grinding on ice with extraction buffer [10 mM Trizma ( $\mathrm{pH} 7.5$ ), $5 \mathrm{mM}$ sodium glutamate, $10 \mathrm{mM} \mathrm{MgSO}_{4}, 1 \mathrm{mM}$ dithiothreitol, $10 \%(\mathrm{v} / \mathrm{v})$ glycerol, and $0.05 \%(\mathrm{v} / \mathrm{v})$ Triton X-100, $\mathrm{pH} 8.0]$. The homogenates were then centrifuged at $4^{\circ} \mathrm{C}, 12,000 \mathrm{~g}$ for $20 \mathrm{~min}$ (O'Neal and Joy, 1973; Bradford, 1976). The soluble protein concentration of the supernatant was measured by the Bradford protein assay using BCA protein assay kit (Pierce Biotechnology, United States) (Minocha and Long, 2004). Bovine serum albumin was used as the standard protein.

For free amino acid contents analysis, the freshly harvested samples ( $\sim 200 \mathrm{mg}$ ) were placed in Eppendorf tubes with $800 \mu \mathrm{l}$ $5 \%(\mathrm{v} / \mathrm{v})$ ice-cold perchloric acid, frozen at $20^{\circ} \mathrm{C}$ and then thawed. 
This process is repeated for three times, and then centrifuged at $13,500 \mathrm{~g}$ for $10 \mathrm{~min}$. Amino acids were analyzed by HPLC according to the method of Minocha and Long (Minocha and Long, 2004). External standards consisted of a mix of 23 amino acids.

The total $\mathrm{N}$ contents were determined using Kjeldahl method (Lynch and Barbano, 1999). The free $\mathrm{NH}_{4}{ }^{+}$was extracted from fresh materials with $60 \%$ (v:v) methanol and determined by the salicylate dichloro-isocyanurate assay (Berthelot reaction) (Husted et al., 2000), whereas the free $\mathrm{NO}_{3}{ }^{-}$was extracted from the fresh materials with hot deionized water $\left(80^{\circ} \mathrm{C}\right)$ and the supernatant was determined by salicylic acid- $\mathrm{H}_{2} \mathrm{SO}_{4}$ method using $\mathrm{KNO}_{3}$ as the standard (Cataldo et al., 2008).

Finally, the Free IAA contents were measured using GS-MS according to the procedure of Muller as described (Pollmann et al., 2009).

\section{Determination of Break Forces}

The breaking forces, which has been reported to be correlated with the cellulose content in stem of maize (Dhugga, 2007), refers to the tensile or bending strength used to break stem. The breaking forces of stem segments were analyzed using YYD-1 plant stalk analyzer according to the manufacturer's instructions (Zhejiang Top Instrument Co., Ltd.).

\section{Scanning Electron Microscopy}

Stem segments were prepared by freeze-drying for scanning electron microscopy (SEM) (S-4800, HITACHI). Dry segments were mounted on aluminum stubs using carbon tape with conductive silver paint applied to the sides to reduce sample charging. The segments were then sputter-coated with gold in an E-100 ion sputter. Imaging was performed at beam accelerating voltages from 12.5 to $25 \mathrm{kV}$. The secondary wall thicknesses of fibers in the SEM micrographs were quantified in a randomly selected area of 45 cells using Image J software ${ }^{4}$.

\section{Determination of Chlorophyll Contents and Photosynthetic Parameters}

To determine chlorophyll contents, leaves were randomly selected and measured for total chlorophyll contents following described previously (Qiu et al., 2013). The photosynthetic rate, stomatal conductance, and transpiration rate were acquired using Li-6400XT portable photosynthesis system (Li-COR) according to the manufacturer's instructions.

\section{Histological Analysis}

Stem sections ( $1 \mu \mathrm{m}$ thick) cut with Leica EM UC6 microtome were stained with $0.01 \%$ Calcofluor White, and the cellulose was observed with an inverted UV fluorescence microscope. Under this condition, only secondary walls exhibited brilliant fluorescence. At the same time, some stem sections $(50 \mu \mathrm{m}$ thick) were stained with phloroglucinol- $\mathrm{HCl}$ for observing lignin, which takes on bright red color under a light microscope. To examine the xylan, $1-\mu \mathrm{m}$-thick sections were

${ }^{4}$ http://rsbweb.nih.gov/ij/ probed with LM10 monoclonal antibodies, which are capable of binding to 4-O-methylglucuronoxylan (McCartney et al., 2005), and detected with fluorescein isothiocyanate-conjugated secondary antibodies. The fluorescence-labeled xylan signals were visualized and imaged with an Olympus DX51 light microscope.

\section{Determination of Contents of Cellulose, Hemicellulose, and Lignin}

The determination of the contents of lignin, cellulose, and hemicellulose was conducted with the ANKOM 2000i Automatic fiber analyzer (Ankom). The procedures are recapitulated as follows.

First, the stems of tobacco were placed in an oven, heated for $10 \mathrm{~min}$ at $100^{\circ} \mathrm{C}$, and then heated at $75^{\circ} \mathrm{C}$ until the weights did not change. Then, the dried stems were ground to powders. $0.5 \mathrm{~g}$ material of each sample was placed in a filter-bag and soaked in acetone for 10-20 min for degreasing. This step was repeated once before the material in the bag was dried for $10 \mathrm{~min}$. After adding $1 \mathrm{~L}$ neutral clean solution (30 g sodium dodecyl sulfate, $18.61 \mathrm{~g}$ ethylene diamine tetraacetic acid disodium salt, $6.81 \mathrm{~g}$ sodium tetraborate, $4.56 \mathrm{~g}$ disodium hydrogen phosphate, $10 \mathrm{ml}$ triethylene glycol, adding $1 \mathrm{~L}$ distillation water and mixing, $\mathrm{pH}$ 6.9-7.1) and $20 \mathrm{~g}$ sodium sulfite in the material, the neutral detergent fiber (NDF) procedure of ANKOM 2000i Automatic Fiber Analyzer (Ankom) was run for $110 \mathrm{~min}$. Then the material in each filter-bag was taken out and placed in an oven, heated for $3 \mathrm{~h}$ at $102^{\circ} \mathrm{C}$. The contents of NDF, including hemicellulose, cellulose and lignin, were subjected to gravimetric analysis.

After the NDF content was determined, the material in each filter-bag was soaked in $1 \mathrm{~L}$ acid solution (20 g cetyltrimethyl ammonium bromide, $1 \mathrm{~L} 1 \mathrm{~N}$ sulphuric acid solution), the acid detergent fiber (ADF) measuring procedure was performed with ANKOM 2000i Automatic Fiber Analyzer. At end of the procedure, the material in each filter-bag was taken out and placed in an oven, heated for $2 \sim 4 \mathrm{~h}$ at $102^{\circ} \mathrm{C}$. The content of ADF, including cellulose and lignin, was subjected to gravimetric analysis. The hemicellulose content was the NDF content minus ADF content.

After the ADF content was determined, the material in each filter-bag was soaked in $72 \%(\mathrm{v} / \mathrm{v})$ sulphuric acid solution and set aside for $3 \mathrm{~h}$. The filter-bag was washed with water for $5 \sim 10$ times until $\mathrm{pH}$ is neutral. The material in each bag was placed in an oven and heated for $4 \mathrm{~h}$ at $102^{\circ} \mathrm{C}$. Then, each material bag was placed in muffle furnace and carbonized for $30 \mathrm{~min}$ at $300^{\circ} \mathrm{C}$ without covering the lid, and then heated to $600^{\circ} \mathrm{C}$. The rest material, acid detergent lignin (ADL), was subjected to gravimetric analysis. The content of cellulose was the content of ADF minus ADL content.

\section{Fiber Length and Width Analysis}

Stem segments with approximate dimension of $2 \mathrm{~mm} \times 2 \mathrm{~mm} \times 30 \mathrm{~mm}$ were harvested and immersed into Franklin solution (1:1 peroxide and glacial acetic acid) with $3.6 \%(\mathrm{~g} / \mathrm{v})$ sodium hypochlorite for $20 \mathrm{~h}$ at $70^{\circ} \mathrm{C}$. Upon 
A

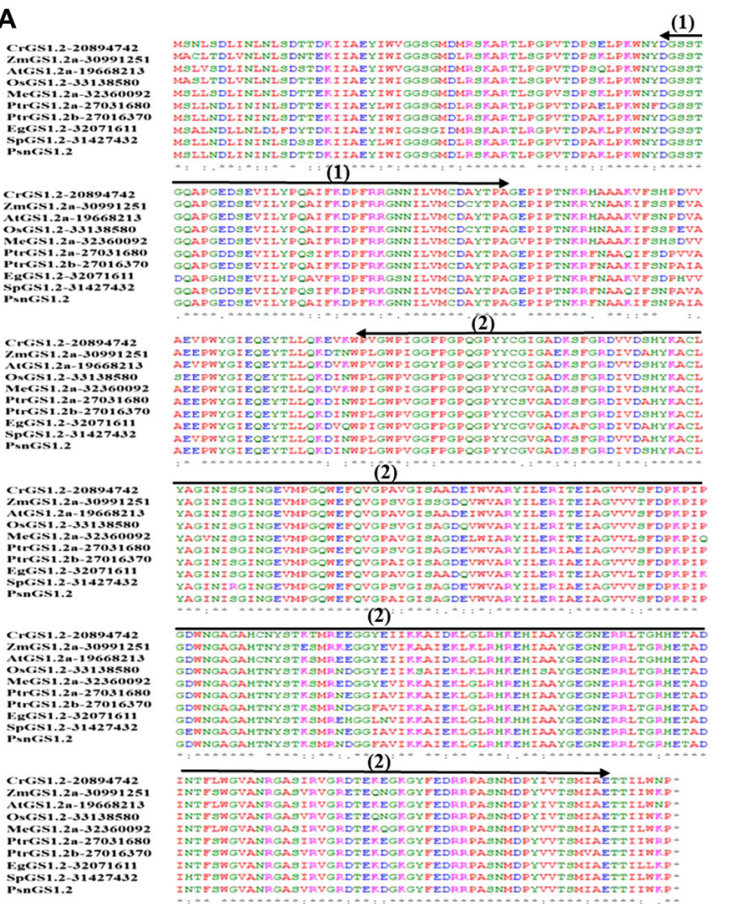

B

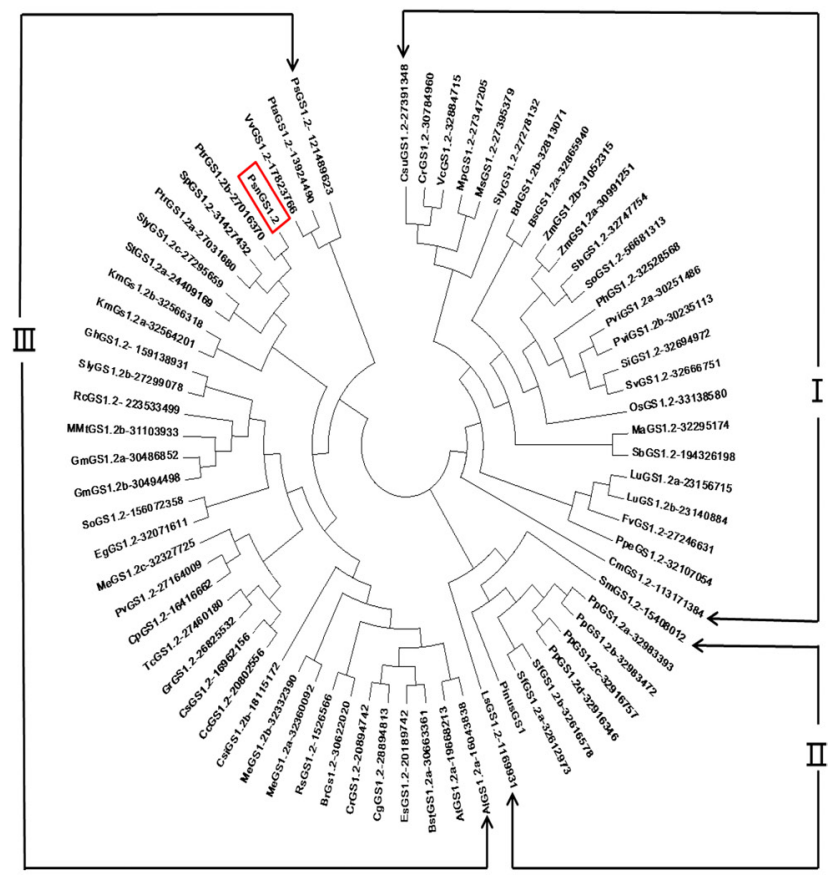

FIGURE 1 | Comparison of the amino acid sequences and phylogenetic relationships among GS1.2 proteins including PsnGS1.2. (A) Comparison of the amino acid sequences among nine GS1.2 proteins including PsnGS1.2, Arrows indicate conserved domains: (1) Glutamine synthetase, beta-Grasp domain (56-97 aa), and (2) Glutamine synthetase, catalytic domain (141-348 aa). Residues are colored according to their polarity properties (neutral non-polar as black, neutral polar as green, acidic as red, and basic as blue). (B) Phylogenetic analysis of 72 GS1.2 proteins from 44 species and the protein sequences of these genes are enclosed in the Supplementary File 1. PsnGS1.2 is shown in a red rectangular frame. The protein sequences and gene IDs were downloaded from the Phytozome database (https://phytozome.jgi.doe.gov/pz/portal.html).

A
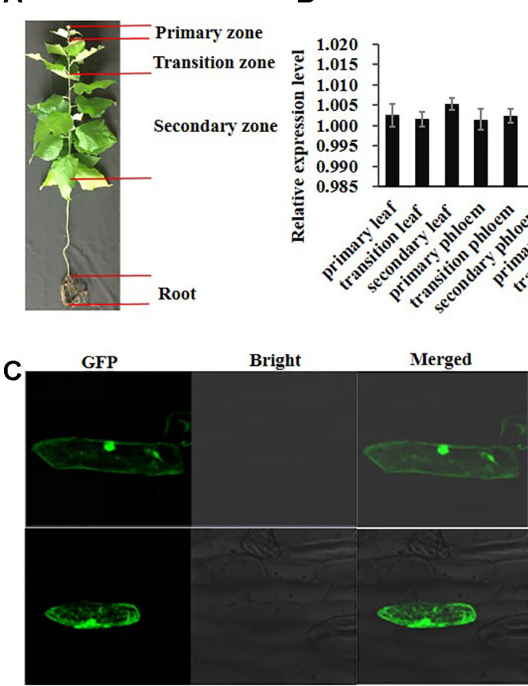

B
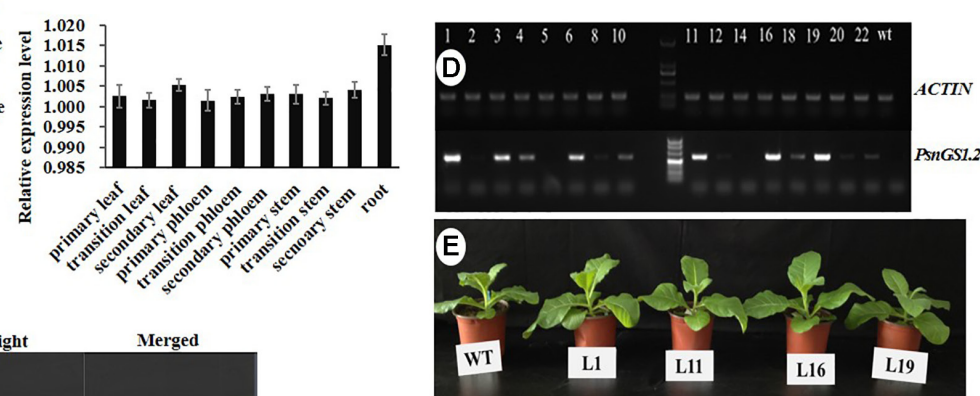

GFP

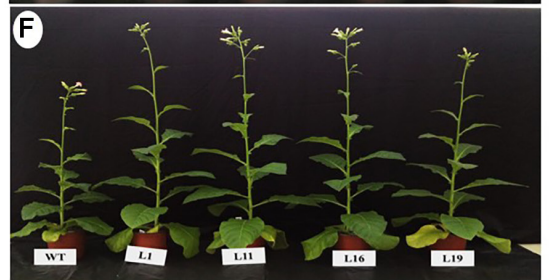

FIGURE 2 | The expression patterns of PSnGS1.2 and morphologies of PSnGS1.2 transgenic tobacco and wild-type. (A) The illustration of different tissues in 1-year-old Populus simonii $\times$ Populus nigra. (B) Quantitative RT-PCR analysis of relative expression levels of PsnGS1.2 in ten tissues of 1-year-old P. simonii $\times$ P. nigra. The PSnACTIN2 was used as an internal control. Error bars represent the standard deviation (SD) of three biological replicates. (C) Subcellular location of PsnGS1.2 proteins in onion epidermal cells. (D) RT-PCR analysis of PsnGS1.2 expression levels in transgenic lines. The numbers from 1 to 22 denote different PSnGS1.2 transgenic lines, WT refers to wild-type tobacco. NtACTIN2 was used as an internal control. Morphologies of 1-month old and 3-month old PsnGS1.2 transgenic lines (E) and WT (F), respectively. 
A

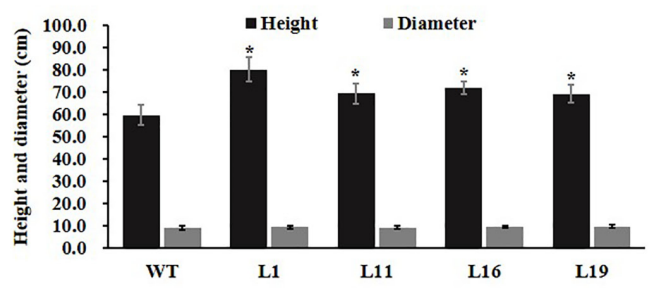

C

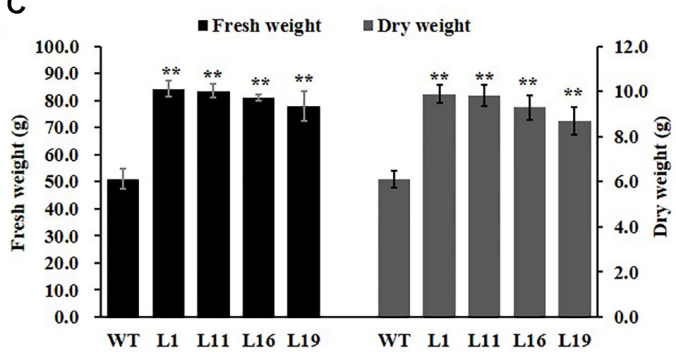

B
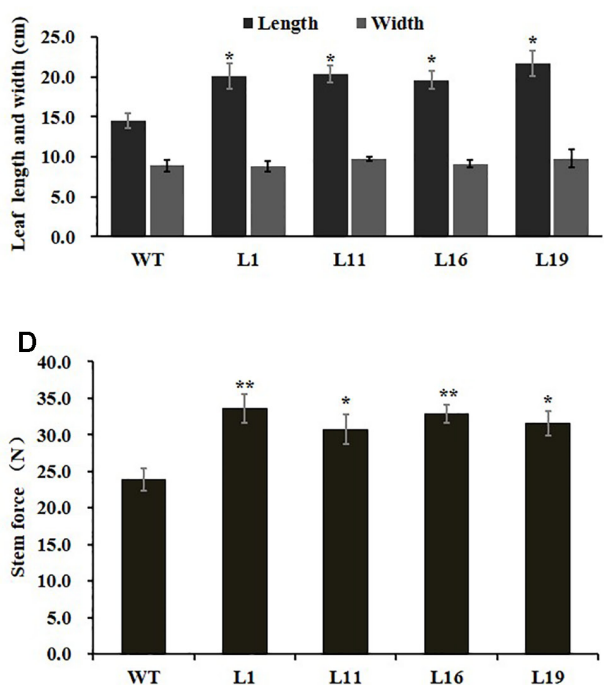

FIGURE 3 | Developmental and growth of PsnGS1.2 transgenic tobacco and WT. (A) Heights and diameters. (B) Leaf lengths and widths. (C) Fresh and dry weights. (D) Breaking forces. Each error bar represents SD of three biological replicates, Asterisks indicate levels of significance $(t$-test; $* P<0.05, * * P<0.01)$.

decanting the solution, the materials were immersed in pure Franklin solution for 4 days at $70^{\circ} \mathrm{C}$, washed in a vacuum with deionized water until the materials reached a neutral $\mathrm{pH}$, dried for $24 \mathrm{~h}$ at $105^{\circ} \mathrm{C}$, and then re-suspended in $10 \mathrm{ml}$ of deionized water. The fiber lengths and widths were obtained by counting 25-40 fibers per second on Fiber Quality Analyzer (FQA).

\section{Statistical Analysis}

The student's $t$-test ${ }^{5}$ was used to statistical analysis. In the figures, mean values and standard deviation (SD) of three biological replicates are shown. Difference between two groups of data for comparisons in this study were evaluated by statistical significance $\left({ }^{*} P<0.05\right)$ or extreme significance $\left({ }^{*} P<0.01\right)$.

\section{RESULTS}

\section{Clone and Characterization of the PsnGS1.2 from $P$. simonii $\times$ P. nigra}

We obtained a PsnGS1.2 cDNA of 1071 bp length from $P$. simonii $\times P$. nigra. The protein sequence of PsnGS1.2 is 98\% identical to the protein encoded by Potri.007G069600.1 in Populous trichocarpa, while cDNA sequence is $93 \%$ identity to Potri.007G069600.1. The deduced protein sequence comparisons demonstrated that the GS1 proteins are highly conserved in different species (Figure 1A). The conserved domain analysis revealed that PsnGS1.2 contained two conserved domains: Glutamine synthetase, beta-Grasp domain (IPR008147) and Glutamine synthetase, catalytic domain (IPR008146) (Figure 1A), which are typical structure characteristics of

\footnotetext{
${ }^{5} \mathrm{http}: / /$ www.graphpad.com/quickcalcs/ttest1.cfm
}

GS proteins (Zhu et al., 2014). These results showed that the PsnGS1.2 belongs to the GS1 subfamily.

Phylogenetic analysis of PsnGS1.2 together with 70 GS1.2 protein sequences from 44 species, including green alga, microbes, and higher plants revealed the existence of three large phylogenetic classes of GS1.2 proteins in these species (Figure 1B). PsnGS1.2 was found in the Clade III, the largest one with 4 sub-clades that comprise of 37 GS1.2 proteins from 32 species. The Clade I and II comprised 25 and 9 GS1.2 proteins from 22 and 5 species, respectively. It was also remarkable that the GS1.2s of the same species did not show up in the same sub-clades or classes. For example, SlyGS1.2-27278132, SlyGS1.2b-27299078, and SlyGS1.2c-27295659 from Solanum lycopersicum. In addition, the GS1.2s from monocotyledon, dicotyledon, herbage, woody plants, and algae species belong to the same sub-clades, indicating that the evolution of GS1.2s is unparalleled with that of species. Moreover, the PsnGS1.2 is not clustered into the same clade with well-characterized Pinus GS1 (Figure 1B), which means that the functions of PsnGS1.2 may not be inferable from other known functional GS1s of woody species.

\section{Tissue-Specific Expression and Subcellular Location of PsnGS1.2}

PsnGS1.2 expression patterns in ten tissues of $P$. simonii $\times P$. nigra were analyzed by quantitative RTPCR (Figure 2A). The results indicated that the expression level of PsnGS1.2 in the roots was the highest among all examined tissues (Figure 2B), indicating that it mainly functions in $\mathrm{N}$ assimilation. In addition, PsnGS1.2 was also expressed in the primary, transition, and the secondary stems, suggesting that PsnGS1.2 can also function in growth and wood formation. 
To verify whether PsnGS1.2 belongs to the category of cytoplasmic GS1s, an in vivo localization experiment was performed by transient overexpression PsnGS1.2 in onion epidermal cells through particle bombardment. As shown in the Figure 2C, the GFP proteins and PsnGS1.2-GFP fusion proteins were both detected primarily in cytosol. Such a result indicated that the PsnGS1.2 encodes a cytosol-localized protein.

\section{Alternation of Growth-Related Traits in PsnGS1.2 Transgenic Tobacco}

To investigate PsnGS1.2's functions in plant growth and development, the PsnGS1.2 transgenic lines were generated in tobacco. In total, $22 \mathrm{~T} 2$ transgenic lines were generated through the cross-hybridization as described (Wei et al., 2015), and were corroborated to harbor PsnGS1.2 by genomic PCR. The PsnGS1.2 expression levels in these transgenic lines were then quantitatively analyzed using RT-PCR. The expression levels of PsnGS1.2 in several transgenic lines, for instance, L1, L11, L16, and L19, were higher than those in other transgenic lines (Figure 2D). Moreover, these PsnGS1.2 transgenic lines exhibited more vigorous growth during vegetative stage than the WT (Figures 2E,F), and thus were chosen for further characterization. However, as shown in Figure 2F, the flowering time had no notable difference between the PsnGS1.2 transgenic lines and the WT (Figure 2F). Although there were no significant differences in the diameters and leaf widths (Figures 3A,B), the PsnGS1.2 transgenic lines had increased heights, leaf lengths, fresh and dry weights, and breaking forces by on average $22.4,20.2,58.7$ and $54.1 \%$, and $23.4 \%$ as compared to WT, respectively (Figures 3A-D). These results indicated that PsnGS1.2 overexpression could accelerate vegetative growth and improve biomass for transgenic lines.

\section{Effects of PsnGS1.2 Overexpression on Biochemical Levels of Transgenic Tobacco}

To examine whether GS enzyme activity was enhanced in PsnGS1.2 transgenic tobacco, we examined the GS activities. As shown in Figure 4A, the GS activities increased $43.6 \%$ in the PsnGS1.2 transgenic lines as compared to the WT, indicating that the mRNAs of PsnGS1.2 could be translated into functional proteins. We further analyzed other biochemical contents to investigate whether the $\mathrm{N}$ assimilation and metabolism changed accordingly owning to the increased GS activity in PsnGS1.2 transgenic lines. The results showed that the contents of total $\mathrm{N}$, soluble protein, total amino acid, free Glu, free Gln, and free $\mathrm{NH}_{4}{ }^{+}$increased 27.8, 32.1, 43.6, 55.4, 86.6, and 35.7\% in the PsnGS1.2 transgenic lines than those in the WT, respectively (Figures 4B-G). In contrast, the free $\mathrm{NO}_{3}{ }^{-}$content of PsnGS1.2 transgenic lines decreased $26.4 \%$ as compared with that of WT (Figure 4H). Moreover, we also performed GC/MS analysis of free IAA content in tobacco. Compared to WT, the PsnGS1.2 transgenic lines displayed a $15.6 \%$ increase of free IAA content (Figure 4I). These results indicated that PsnGS1.2 overexpression led to significant changes in $\mathrm{N}$ assimilation and metabolism, amino acid homeostasis, and also a reinforcement of free IAA biosynthesis in transgenic tobacco.

Since there were obvious differences in the leaf lengths between the PsnGS1.2 transgenic lines and WT, we suspected the increased leaf lengths were primarily caused by the enlargement of leaf cells. The leaf cell sizes and structures were examined using SEM. The result indicated that the epidermis cells at upper leaf surfaces of PsnGS1.2 transgenic lines were much larger than those of WT (Figures 5A-D), while the stomatal numbers per unit area were decreased about 30\% (Figures 5C,D), but no changes in the stomatal sizes (Figures 5E,F). The anatomical changes in the cross sections of leaves showed that the thickness, volume of palisade and spongy parenchyma in PsnGS1.2 transgenic lines obviously increased compared to WT (Figures 5G-L). Considering that the changes of leaf structures in PsnGS1.2 transgenic lines might affect the chlorophyll contents and photosynthetic parameters, we measured the chlorophyll content, stomatal conductance, transpiration rate, and photosynthetic rate, which were $29.3,40.7,36.4$, and $48.6 \%$ higher than those of WT, respectively (Figures 6A-D). These results suggested PsnGS1.2 overexpression had influence on leaf structures and photosynthesis of transgenic tobacco.

\section{Changes of Secondary Cell Walls and Fiber Characteristics in PsnGS1.2 Transgenic Tobacco}

Owning to the alternations of growth traits of PsnGS1.2 transgenic lines, we further examined secondary walls and fiber characteristics in the stems of transgenic lines. Examination of SEM demonstrated that the PsnGS1.2 transgenic lines exhibited $40.7 \%$ thicker secondary walls than those of WT (Figures 7A-F, 8A). To identify which component caused augmented secondary cell wall thickening, we used calcofluor and phloroglucinol-HCl to stain cellulose and lignin, respectively, and monoclonal antibody LM10 to label xylan immunologically. The results showed that the lignin content decreased, whereas the deposit of cellulose and hemicellulose increased in the PsnGS1.2 transgenic lines as compared to the WT (Figures 7G-L). Chemical analysis implicated that the contents of cellulose and hemicellulose increased 10.1 and $9.7 \%$, respectively, and the lignin content reduced $23.4 \%$ in the PsnGS1.2 transgenic lines as compared to these in the WT (Figure 8B). We also found that the average length and width of fiber in PsnGS1.2 transgenic lines were about 20 and $18 \%$ more than those in the WT, respectively (Figure 8C). Taken together, these results implicated that PsnGS1.2 overexpression had significant influence on secondary walls and fiber characteristics of transgenic tobacco.

\section{Alternation of Gene Expression in PsnGS1.2 Transgenic Tobacco}

Consistent with changes of secondary walls and fiber characteristics, the expression levels of genes participating in secondary wall principal components biosynthesis, including cellulose (CesA4, CesA7, and CesA8) and hemicellulose (FRA8, $I R X 9$, and $I R X 10$ ), were significantly up-regulated in PsnGS1.2 transgenic lines compared to those in WT (Figure 8D). In 


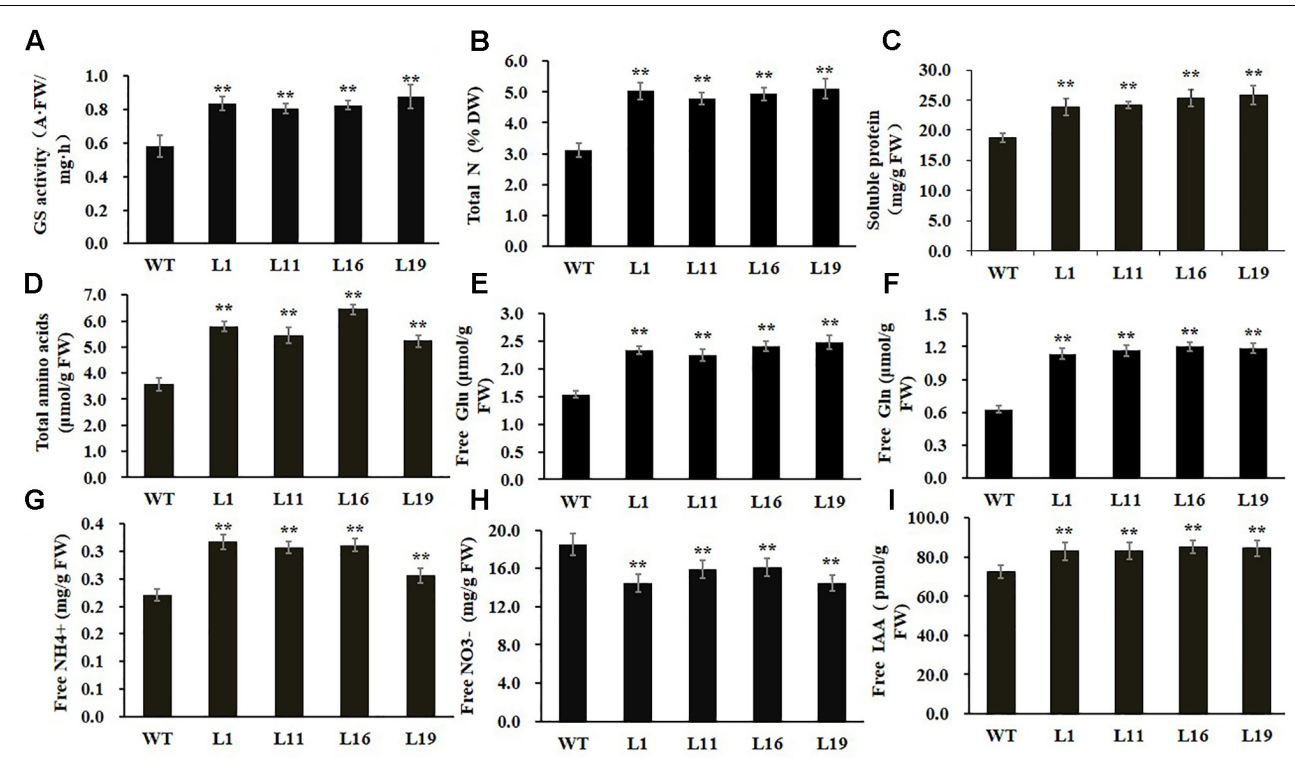

FIGURE 4 | Biochemical levels of PsnGS1.2 transgenic tobacco and WT. (A) Total GS activity. (B) Total N content. (C) Soluble protein content. (D) Total amino acid content. (E) Free Glu content. (F) Free Gln content. (G) Free $\mathrm{NH}_{4}{ }^{+}$content. (H) Free $\mathrm{NO}_{3}{ }^{-}$content. (I) Free IAA content. Each error bar represents $\mathrm{SD}$ of three biological replicates, Asterisks indicate levels of significance ( $t$-test; $\left.{ }^{*} P<0.05,{ }^{* *} P<0.01\right)$.
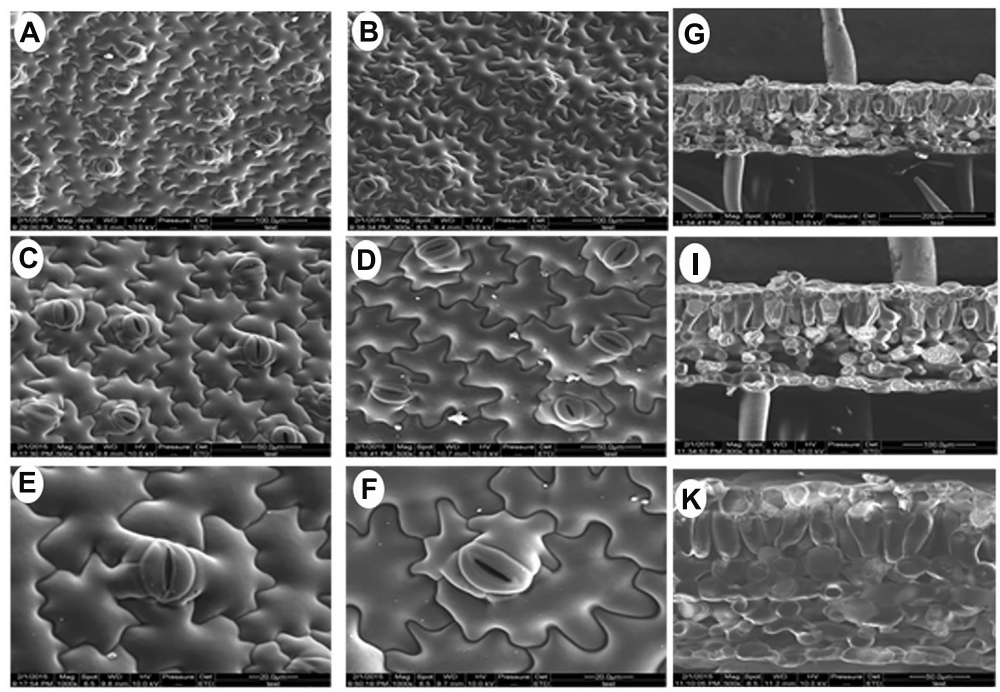
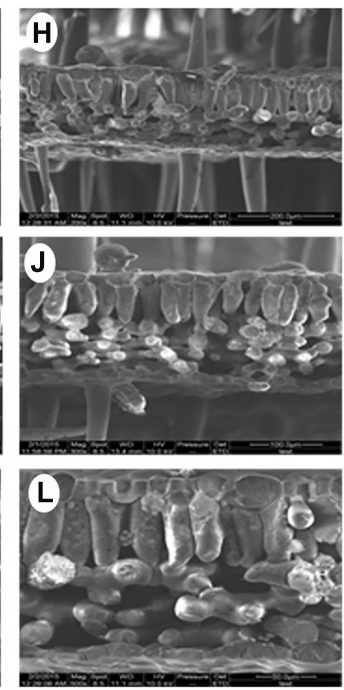

FIGURE 5 | Leaf ultrastructure of PSnGS1.2 transgenic tobacco and WT. Scanning electron microscope (SEM) of leaf epidermis in WT (A,C,E) and PsnGS1.2 transgenic tobacco (B,D,F). SEM of leaf cross sections in WT (G,I,K) and PsnGS1.2 transgenic tobacco (H,J,L). (A,B,G,H), 300 x magnification; (C,D,I,J), 500x magnification; (E,F,K,L), 1000x magnifications.

contrast, the expression levels of lignin biosynthetic genes such as PAL1, PAL4, CAD14, CAD19, 4CL1, 4CL2, HCT, and CCoAOMT1 showed significant reduction (Figure 8E). Moreover, the genes including ExpansinA, ExpansinB, TIP1;3, TIP1;4, XTH5, and XTH8 involved in the cell expansion and elongation were significantly up-regulated, whereas the genes including XSP1, XCP2, SCPL45, and SCPL49 involved in programmed cell death were notably down-regulated (Figure 8F). In addition, the expression levels of APP11 and
$A M Y 1$, which play important roles in $\mathrm{N}$ transportation during xylem formation (Couturier et al., 2010) and starch breakdown (Castro-Rodriguez et al., 2016), respectively, were significantly up-regulated. We also analyzed the expression level of ASA1, which catalyzes a rate-limiting step of IAA biosynthesis (Sun et al., 2009), and found its expression level was remarkably increased in the PsnGS1.2 transgenic lines compared with that in the WT (Figure 8D). These results aligned well with the alternations of both $\mathrm{N}$ assimilation and metabolism, growth 

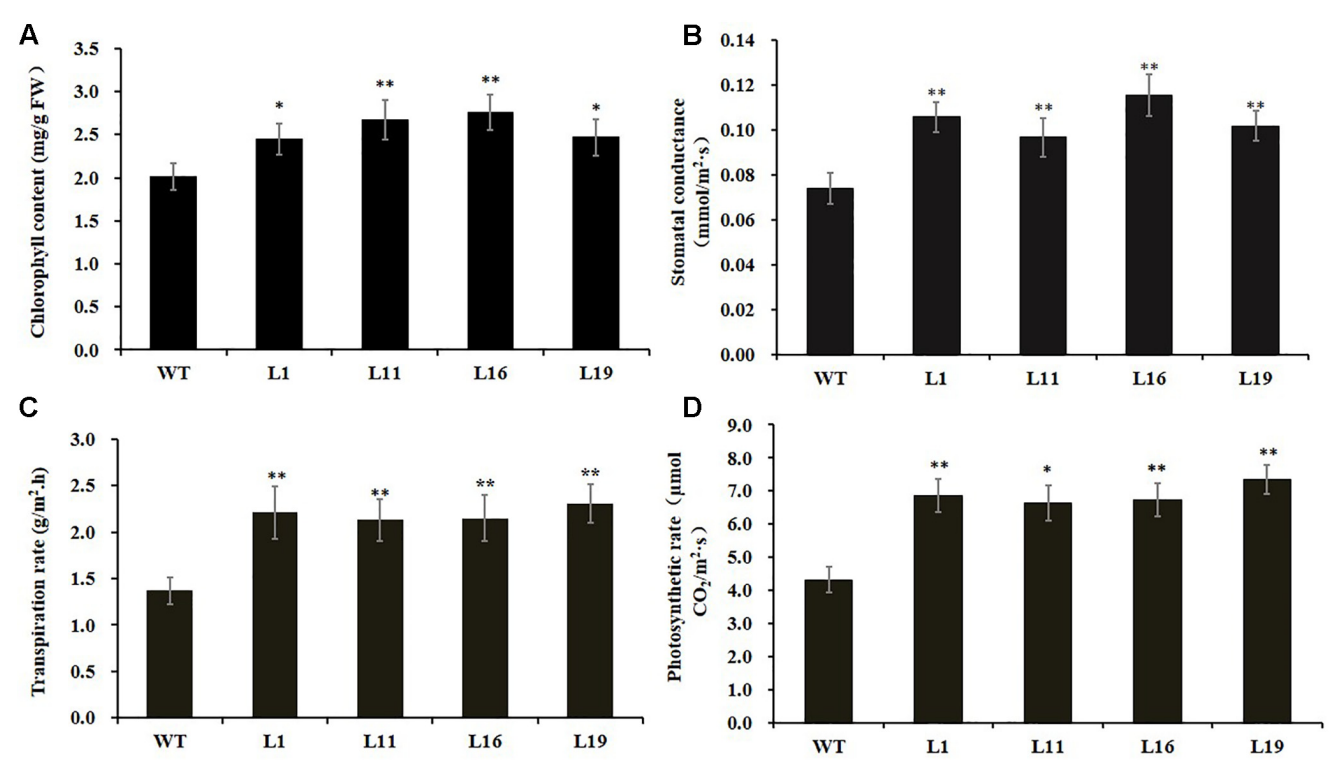

FIGURE 6 | Chlorophyll content and photosynthetic parameters of PsnGS1.2 transgenic tobacco and WT. (A) Content of chlorophyll. (B) Stomatal conductance. (C) Transpiration rate. (D) Photosynthetic rates. Each error bar represents SD of three biological replicates. Asterisks indicate levels of significance $\left(t\right.$-test; ${ }^{*} P<0.05$, $* * P<0.01)$.
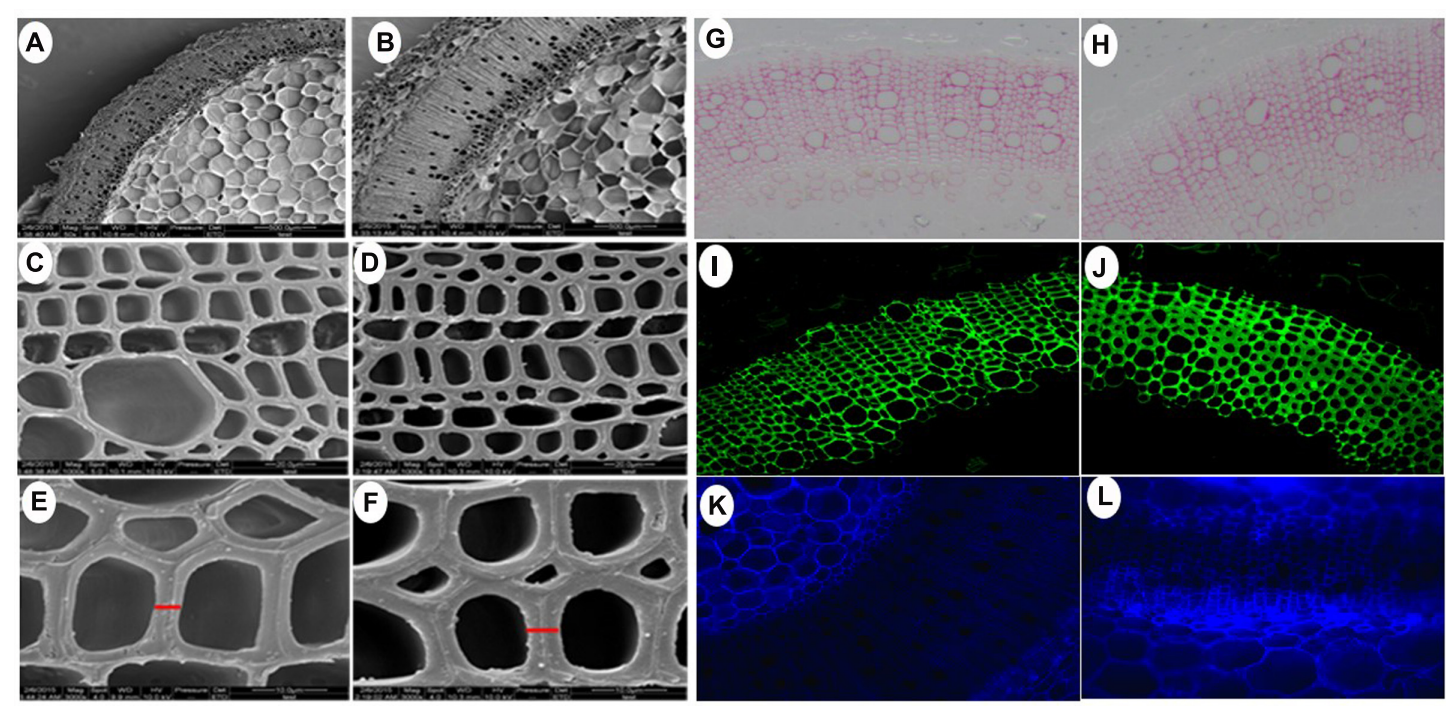

FIGURE 7 | Secondary cell wall thickness and composition in stems of PsnGS1.2 transgenic tobacco and WT. SEM of cross stem sections of WT (A,C,E) and PsnGS1.2 transgenic lines (B,D,F). (A,B), 1000x magnification; (C,D), 3000x magnification; (E,F), 5000x magnification. Lignin (red color) stained with Phloroglucinol-HCl (G,H), Xylan (green color) stained with LM10 xylan monoclonal antibody (I,J), Cellulose in stem sections stained with Calcofluor White (K,L). $(\mathbf{G}, \mathbf{I}, \mathbf{K})$, represent WT; $(\mathbf{H}, \mathbf{J}, \mathbf{L})$, represent PsnGS1.2 transgenic tobacco.

traits, and secondary walls and fiber characteristics observed in the PsnGS1.2 transgenic tobacco.

\section{DISCUSSION}

As the first enzyme in the $\mathrm{N}$ assimilatory pathway, GS1s have been proven to play a critical partition role in plant $\mathrm{N}$ assimilation and metabolism, growth, and productivity (Fuentes et al., 2001; Habash et al., 2001; Oliveira et al., 2002; Man et al., 2005; Molina-Rueda and Kirby, 2015; Seger et al., 2015; Guan et al., 2016). In this study, a cytoplasmic GS1 type protein PsnGS1.2, was isolated from $P$. simonii $\times$ P. nigra and characterized by overexpression in tobacco. We observed a number of phenotypic, biochemical, physiological, as well as anatomical changes in the PsnGS1.2 transgenic tobacco, which resembled the changes that 

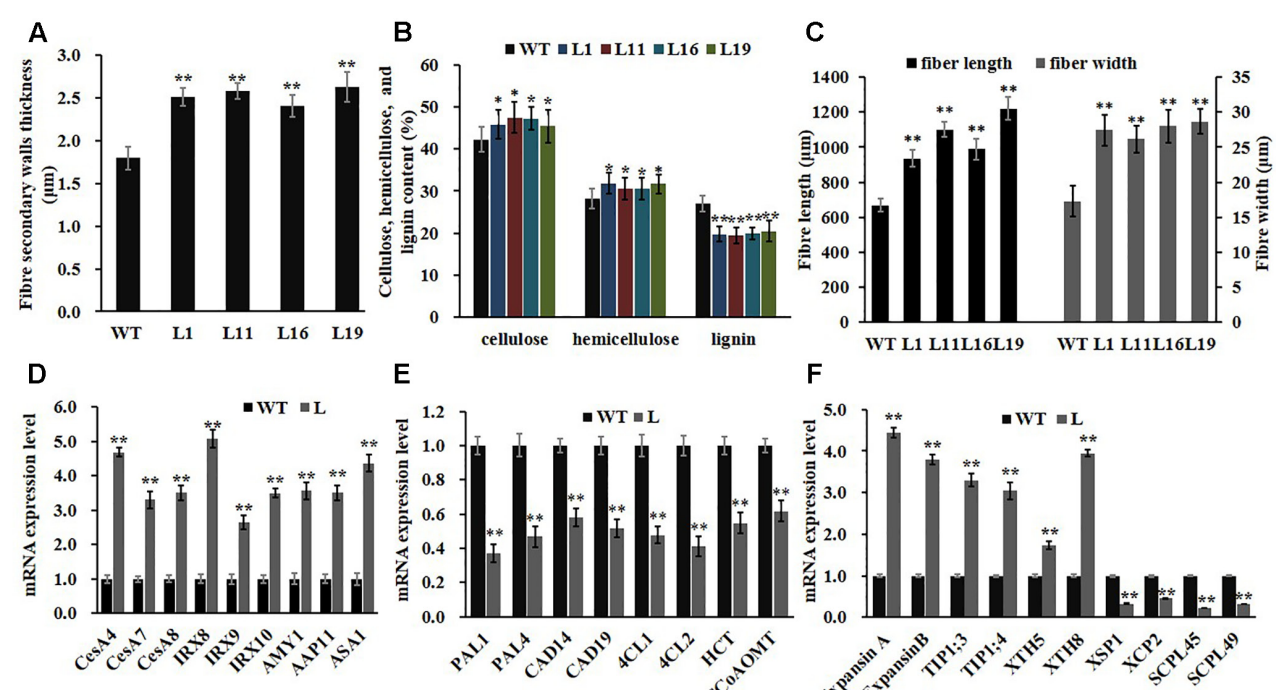

\section{E}
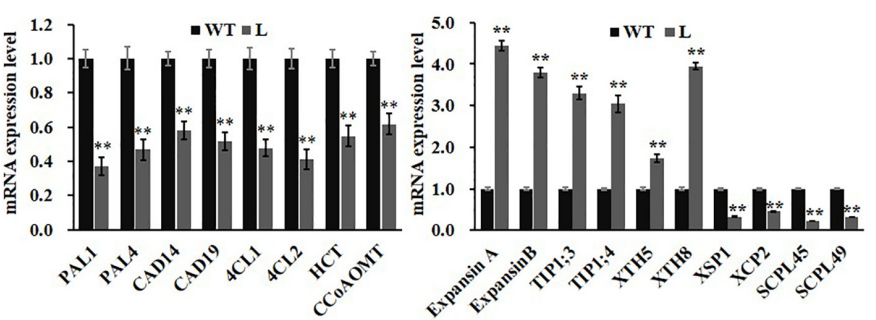

FIGURE 8 | Fiber characteristics and gene expression involved in wood formation and N metabolism in stems of PsnGS1.2 transgenic tobacco and WT. (A) Secondary wall thicknesses. (B) Contents of cellulose, hemicellulose, and lignin. (C) Fiber lengths and widths. (D) Expression levels of genes involved in cellulose (CESA4, CESA7, and CESA8) and hemicellulose (IRX8, IRX9, and IRX10) biosynthesis, $\beta$-amylase gene (AMY1), a membrane transport protein gene (AAP11), and a rate-limiting IAA biosynthesis gene (ASA1). (E) Expression levels of genes involved in lignin biosynthesis (PAL1, PAL4, CAD14, CAD19, 4CL1, 4CL2, HCT, and CCOAOMT1). (F) Expression levels of genes involved in cell expansion (ExpansinA, ExpansinB, TIP1;3, TIP1;4, XTH5, and XTH8) and programmed cell death (XSP1, XCP2, SCPL45, and SCPL49). NtACTIN2 was used as an internal control. The expression of level of each gene in the WT was set to 1, Each error bar represents SD of three biological replicates, Asterisks indicate levels of significance (t-test; $\left.{ }^{*} P<0.05,{ }^{* *} P<0.01\right)$.

were observed in other GS1s transgenic plants (Man et al., 2005; Tabuchi et al., 2007; Zhu et al., 2014; Molina-Rueda and Kirby, 2015). At same time, we also found some distinct functions of PsnGS1.2. For example, the free $\mathrm{NH}_{4}{ }^{+}$contents in the PsnGS1.2 transgenic tobacco increased rather decreased, as observed in other studies (Lothier et al., 2011; Molina-Rueda and Kirby, 2015). We speculated that this difference is probably caused by distinct expression pattern of PsnGS1.2. The PsnGS1.2 is predominantly expressed in roots, and may indirectly accelerate $\mathrm{NO}_{3}{ }^{-}$reduction to $\mathrm{NH}_{4}{ }^{+}$through up-regulation the nitrate transporter genes in roots and nitrate reductase (NR) genes in leaves of PsnGS1.2 transgenic tobacco, as what was described for OSGS1;2 (Cai et al., 2009). This led to the decreased $\mathrm{NO}_{3}{ }^{-}$ content and increased $\mathrm{NH}_{4}{ }^{+}$content. In contrast, the GS1s that are primarily expressed in phloem tissue of stems may function in the translocation of the $\mathrm{N}$ compounds from roots to leaves, and thus their overexpression result in an increase of $\mathrm{NH}_{4}{ }^{+}$ and $\mathrm{NO}_{3}{ }^{-}$contents in the leaves (Lothier et al., 2011; MolinaRueda and Kirby, 2015). In addition, there are also some GS1s, which are constitutively expressed in leaves and play a primary role in the synthesis of Gln using $\mathrm{NH}_{4}{ }^{+}$that is converted from $\mathrm{NO}_{3}{ }^{-}$, and their overexpression causes both $\mathrm{NH}_{4}{ }^{+}$and $\mathrm{NO}_{3}{ }^{-}$ contents decreased in transgenic plants (Martin et al., 2006; Zhu et al., 2014). In addition, it is noteworthy that there are also some GS1.2 genes that do not have any effects on $\mathrm{N}$ assimilation and metabolism, and growth when they are overexpressed (Ortega et al., 2001; Fei et al., 2003).

When PsnGS1.2 was overexpressed in tobacco, the direct effect was that the $\mathrm{N}$ assimilation and metabolic products, such as total $\mathrm{N}$, soluble proteins, total amino acids, free $\mathrm{NH}_{4}{ }^{+}$, free
Glu and Gln contents were significantly altered. Consequently, in order to maintain a balanced metabolism between $\mathrm{N}$ and $\mathrm{C}$ in response to the increased $\mathrm{N}$ assimilation and alternated $\mathrm{N}$ compounds, the PsnGS1.2 transgenic tobacco exhibited a series of phenotypical and physiological changes, such as larger leaf sizes, altered leaf structural features, increased chlorophyll contents, and augmented photosynthesis to improve carbon skeleton assimilation, which resulted in reinforced vegetative growth and biomass production. These results also confirmed previous studies that the augmented $\mathrm{N}$ assimilation can accumulate more biomass through promoting photosynthesis that produces more carbon skeletons and leads to the augmented synthesis of starch and sucrose (Nunes-Nesi et al., 2010; Bao et al., 2014).

The PsnGS1.2 transgenic tobacco contained more cellulose and hemicellulose and reduced lignin, indicating there was a reinforcement of carbon flux to cellulose and hemicellulose instead of lignin biosynthesis pathway. It has been reported that the cellulose contents are positively correlated with vegetative biomass (Novaes et al., 2009), and the increased biomass is concomitant with reduced levels of lignin (Novaes et al., 2010). Thus, the increased contents of cellulose and hemicellulose could contribute directly to the increased biomass in PsnGS1.2 transgenic tobacco. Moreover, the changes of cellulose and lignin contents did not show any adverse effects on the growth and development for PsnGS1.2 transgenic tobacco, as they exhibited normal vegetative growths and flowers. As tensile strength is correlated with cellulose content of plant stems (Dhugga, 2007; Voelker et al., 2011), the increase in cellulose of PsnGS1.2 transgenic tobacco could counteract some mechanical strength reduction due to the decrease of lignin, as indicated in other 
studies (Ambavaram et al., 2011; Welker et al., 2015). Moreover, we also observed that the PsnGS1.2 transgenic tobacco displayed longer and wider fibers. On the contrary, in pine GS1a transgenic poplar, the fiber lengths increased but the fiber widths did not change significantly (Coleman et al., 2012). It has also been reported that the transcriptome during poplar growth was notably changed in response to high $\mathrm{N}$ availability, resulting in alternations of large number of genes in different biological pathways (Cooke et al., 2003; Castro-Rodriguez et al., 2016). As PsnGS1.2 overexpression caused notable alternation of $\mathrm{N}$ assimilation and metabolism, carbohydrate accumulation, and secondary walls and fiber characteristics, we reasoned that the expression of key genes related to these traits should be altered in the PsnGS1.2 transgenic tobacco. Because the APP11 encodes an amino acid transporter that plays a critical role in $\mathrm{N}$ transportation during the process of xylem differentiation (Couturier et al., 2007), and AMY1 functions in starch mobilization (Lloyd et al., 2005), the increased expressions of APP11 and AMY1 in PsnGS1.2 transgenic tobacco could account for the alternations of $\mathrm{N}$ and $\mathrm{C}$ metabolism. Moreover, the genes participating in the secondary wall formation, fiber cell expansion and extension, and programmed cell death exhibited notable alternations in PsnGS1.2 transgenic tobacco. These results indicated that the PsnGS1.2 overexpression had an influence on the gene expression of $\mathrm{N}$ and $\mathrm{C}$ metabolic pathway, as what were observed in previous study (Castro-Rodriguez et al., 2016).

The expression level of $A S A 1$, which catalyzes a rate-limiting step of IAA biosynthesis (Sun et al., 2009), was significantly up-regulated in PsnGS1.2 transgenic tobacco. This is similar to what was observed in Pinus GS1a transgenic poplar (Man et al., 2011). Moreover, the PsnGS1.2 transgenic tobacco exhibited significantly increased contents of Gln which is known to play an important role in enhancing IAA biosynthesis (Mihaljevic et al., 2011). These results suggested PsnGS1.2 overexpression could promote IAA biosynthesis and lead to increased IAA content in

\section{REFERENCES}

Ambavaram, M. M., Krishnan, A., Trijatmiko, K. R., and Pereira, A. (2011). Coordinated activation of cellulose and repression of lignin biosynthesis pathways in rice. Plant Physiol. 155, 916-931. doi: 10.1104/pp.110.168641

Appenzeller, L., Doblin, M., Barreiro, R., Wang, H. Y., Niu, X. M., Kollipara, K., et al. (2004). Cellulose synthesis in maize: isolation and expression analysis of the cellulose synthase (CesA) gene family. Cellulose 11, 287-299. doi: 10.1023/B: CELL.0000046417.84715.27

Aspeborg, H., Schrader, J., Coutinho, P. M., Stam, M., Kallas, A., Djerbi, S., et al. (2005). Carbohydrate-active enzymes involved in the secondary cell wall biogenesis in hybrid aspen. Plant Physiol. 137, 983-997. doi: 10.1104/pp.104. 055087

Bao, A., Zhao, Z., Ding, G., Shi, L., Xu, F., and Cai, H. (2014). Accumulated expression level of cytosolic glutamine synthetase 1 gene (OsGS1;1 or OsGS1;2) alter plant development and the carbon-nitrogen metabolic status in rice. PLOS ONE 9:e95581. doi: 10.1371/journal.pone.0095581

Bernard, S. M., Moller, A. L., Dionisio, G., Kichey, T., Jahn, T. P., Dubois, F., et al. (2008). Gene expression, cellular localisation and function of glutamine synthetase isozymes in wheat (Triticum aestivum L.). Plant Mol. Biol. 67, 89-105. doi: 10.1007/s11103-008-9303-y
PsnGS1.2 transgenic tobacco. Considering the roles of IAA in plant growth, development, and wood formation (Moyle et al., 2002; Zhao, 2010), we speculate that the increased IAA content may play a significant role in promoting vegetative growth and secondary wall formation, and fiber characteristics alternation in PsnGS1.2 transgenic tobacco. However, this hypothesis is still lack of direct biological evidence and need to be further investigated. At the same time, it is also intriguing to study the performance of PsnGS1.2 transgenic tobacco under low $\mathrm{N}$ condition.

\section{AUTHOR CONTRIBUTIONS}

TL and LL: participated in experiment setup and measurements. MW: participated in experiment measurements. YL: participated in the data analysis. ZQ: participated in editing of the manuscript. $\mathrm{CY}$ : revised the manuscript. HW: performed data analysis and wrote manuscript. ZW: designed the experiments, performed data analysis, and wrote manuscript. All the authors read and approved the final version of the manuscript.

\section{FUNDING}

The work was funded by the National Nature Science Fund (31770640), the 111 Project (B16010), the Foundation Research Fund for the Central Universities of China (No. 2572016EAJ2), and Returned Overseas Researcher Fund of Heilongjiang Province (LC2015012).

\section{SUPPLEMENTARY MATERIAL}

The Supplementary Material for this article can be found online at: https://www.frontiersin.org/articles/10.3389/fpls.2018.00009/ full\#supplementary-material

Betti, M., Garcia-Calderon, M., Perez-Delgado, C. M., Credali, A., Pal'oveBalang, P., Estivill, G., et al. (2014). Reassimilation of ammonium in Lotus japonicus. J. Exp. Bot. 65, 5557-5566. doi: 10.1093/jxb/eru260

Black, B. L., Fuchigami, L. H., and Coleman, G. D. (2002). Partitioning of nitrate assimilation among leaves, stems and roots of poplar. Tree Physiol. 22, 717-724. doi: 10.1093/treephys/22.10.717

Bradford, M. M. (1976). A rapid and sensitive method for the quantitation of microgram quantities of protein utilizing the principle of proteindye binding. Anal. Biochem. 72, 248-254. doi: 10.1016/0003-2697(76) 90527-3

Cai, H., Zhou, Y., Xiao, J., Li, X., Zhang, Q., and Lian, X. (2009). Overexpressed glutamine synthetase gene modifies nitrogen metabolism and abiotic stress responses in rice. Plant Cell Rep. 28, 527-537. doi: 10.1007/s00299-0080665-z

Castro-Rodriguez, V., Garcia-Gutierrez, A., Canales, J., Avila, C., Kirby, E. G., and Canovas, F. M. (2011). The glutamine synthetase gene family in Populus. BMC Plant Biol. 11:119. doi: 10.1186/1471-2229-11-119

Castro-Rodriguez, V., Garcia-Gutierrez, A., Canales, J., Canas, R. A., Kirby, E. G., Avila, C., et al. (2016). Poplar trees for phytoremediation of high levels of nitrate and applications in bioenergy. Plant Biotechnol. J. 14, 299-312. doi: $10.1111 /$ pbi. 12384 
Cataldo, D. A., Maroon, M., Schrader, L. E., and Youngs, V. L. (2008). Rapid colorimetric determination of nitrate in plant tissue by nitration of salicylic acid1. Commun. Soil Sci. Plant Anal. 6, 71-80. doi: 10.1080/00103627509366547

Coleman, H. D., Canovas, F. M., Man, H., Kirby, E. G., and Mansfield, S. D. (2012). Enhanced expression of glutamine synthetase (GS1a) confers altered fibre and wood chemistry in field grown hybrid poplar (Populus tremula X alba) (717-1B4). Plant Biotechnol. J. 10, 883-889. doi: 10.1111/j.1467-7652.2012. 00714.x

Cooke, J. E. K., Brown, K. A., Wu, R., and Davis, J. M. (2003). Gene expression associated with $\mathrm{N}$-induced shifts in resource allocation in poplar. Plant Cell Environ. 26, 757-770. doi: 10.1046/j.1365-3040.2003.01012.x

Couturier, J., De Fay, E., Fitz, M., Wipf, D., Blaudez, D., and Chalot, M. (2010). PtAAP11, a high affinity amino acid transporter specifically expressed in differentiating xylem cells of poplar. J. Exp. Bot. 61, 1671-1682. doi: 10.1093/ jxb/erq036

Couturier, J., Montanini, B., Martin, F., Brun, A., Blaudez, D., and Chalot, M. (2007). The expanded family of ammonium transporters in the perennial poplar plant. New Phytol. 174, 137-150. doi: 10.1111/j.1469-8137.2007.01992.x

Dhugga, K. S. (2007). Maize biomass yield and composition for biofuels. Crop Sci. 47, 2211-2227. doi: 10.2135/cropsci2007.05.0299

Dubois, F., Brugiere, N., Sangwan, R. S., and Hirel, B. (1996). Localization of tobacco cytosolic glutamine synthetase enzymes and the corresponding transcripts shows organ- and cell-specific patterns of protein synthesis and gene expression. Plant Mol. Biol. 31, 803-817. doi: 10.1007/BF00019468

Fei, H., Chaillou, S., Hirel, B., Mahon, J. D., and Vessey, J. K. (2003). Overexpression of a soybean cytosolic glutamine synthetase gene linked to organ-specific promoters in pea plants grown in different concentrations of nitrate. Planta 216, 467-474.

Fuentes, S. I., Allen, D. J., Ortiz-Lopez, A., and Hernandez, G. (2001). Overexpression of cytosolic glutamine synthetase increases photosynthesis and growth at low nitrogen concentrations. J. Exp. Bot. 52, 1071-1081. doi: 10.1093/ jexbot/52.358.1071

Guan, M., De Bang, T. C., Pedersen, C., and Schjoerring, J. K. (2016). Cytosolic glutamine synthetase Gln1;2 is the main isozyme contributing to GS1 activity and can be up-regulated to relieve ammonium toxicity. Plant Physiol. 171, 1921-1933. doi: 10.1104/pp.16.01195

Habash, D. Z., Massiah, A. J., Rong, H. L., Wallsgrove, R. M., and Leigh, R. A. (2001). The Role of Cytosolic Glutamine Synthetase in Wheat. Wellesbourne: Association of Applied Biologists.

Hacke, U. G., Plavcova, L., Almeida-Rodriguez, A., King-Jones, S., Zhou, W., and Cooke, J. E. (2010). Influence of nitrogen fertilization on xylem traits and aquaporin expression in stems of hybrid poplar. Tree Physiol. 30, 1016-1025. doi: 10.1093/treephys/tpq058

Hirel, B., Marsolier, M. C., Hoarau, A., Hoarau, J., Brangeon, J., Schafer, R., et al. (1992). Forcing expression of a soybean root glutamine synthetase gene in tobacco leaves induces a native gene encoding cytosolic enzyme. Plant Mol. Biol. 20, 207-218. doi: 10.1007/BF00014489

Hirel, B., Mcnally, S. F., Gadal, P., Sumar, N., and Stewart, G. R. (1984). Cytosolic glutamine synthetase in higher plants. A comparative immunological study. Eur. J. Biochem. 138, 63-66. doi: 10.1111/j.1432-1033.1984.tb07881.x

Husted, S., Hebbern, C. A., Mattsson, M., and Schjoerring, J. K. (2000). A critical experimental evaluation of methods for determination of $\mathrm{NH}_{4}{ }^{+}$in plant tissue, xylem sap and apoplastic fluid. Physiol. Plant. 109, 167-179. doi: 10.1034/j. 1399-3054.2000.100209.x

Ishiyama, K., Inoue, E., Tabuchi, M., Yamaya, T., and Takahashi, H. (2004a). Biochemical background and compartmentalized functions of cytosolic glutamine synthetase for active ammonium assimilation in rice roots. Plant Cell Physiol. 45, 1640-1647.

Ishiyama, K., Inoue, E., Watanabe-Takahashi, A., Obara, M., Yamaya, T., and Takahashi, H. (2004b). Kinetic properties and ammonium-dependent regulation of cytosolic isoenzymes of glutamine synthetase in Arabidopsis. J. Biol. Chem. 279, 16598-16605.

Jackson, L. E., Burger, M., and Cavagnaro, T. R. (2008). Roots, nitrogen transformations, and ecosystem services. Annu. Rev. Plant Biol. 59, 341-363. doi: 10.1146/annurev.arplant.59.032607.092932

Kolosova, N., Miller, B., Ralph, S., Ellis, B. E., Douglas, C., Ritland, K., et al. (2004). Isolation of high-quality RNA from gymnosperm and angiosperm trees. Biotechniques 36, 821-824.
Liao, Z., Chen, M., Guo, L., Gong, Y., Tang, F., Sun, X., et al. (2004). Rapid isolation of high-quality total RNA from taxus and ginkgo. Prep. Biochem. Biotechnol. 34, 209-214. doi: 10.1081/PB-200026790

Livak, K. J., and Schmittgen, T. D. (2001). Analysis of relative gene expression data using real-time quantitative PCR and the $2^{-\Delta \Delta C} \mathrm{~T}$ method. Methods 25, 402-408. doi: 10.1006/meth.2001.1262

Lloyd, J. R., Kossmann, J., and Ritte, G. (2005). Leaf starch degradation comes out of the shadows. Trends Plant Sci. 10, 130-137. doi: 10.1016/j.tplants.2005.01.001

Lothier, J., Gaufichon, L., Sormani, R., Lemaitre, T., Azzopardi, M., Morin, H., et al. (2011). The cytosolic glutamine synthetase GLN1;2 plays a role in the control of plant growth and ammonium homeostasis in Arabidopsis rosettes when nitrate supply is not limiting. J. Exp. Bot. 62, 1375-1390. doi: 10.1093/jxb/erq299

Lynch, J. M., and Barbano, D. M. (1999). Kjeldahl nitrogen analysis as a reference method for protein determination in dairy products. J. AOAC Int. 82, 1389-1398.

Maiti, I. B., Murphy, J. F., Shaw, J. G., and Hunt, A. G. (1993). Plants that express a potyvirus proteinase gene are resistant to virus infection. Proc. Natl. Acad. Sci. U.S.A. 90, 6110-6114. doi: 10.1073/pnas.90.13.6110

Man, H. M., Boriel, R., El-Khatib, R., and Kirby, E. G. (2005). Characterization of transgenic poplar with ectopic expression of pine cytosolic glutamine synthetase under conditions of varying nitrogen availability. New Phytol. 167, 31-39. doi: 10.1111/j.1469-8137.2005.01461.x

Man, H. M., Pollmann, S., Weiler, E. W., and Kirby, E. G. (2011). Increased glutamine in leaves of poplar transgenic with pine GS1a caused greater anthranilate synthetase alpha-subunit (ASA1) transcript and protein abundances: an auxin-related mechanism for enhanced growth in GS transgenics? J. Exp. Bot. 62, 4423-4431. doi: 10.1093/jxb/err026

Martin, A., Lee, J., Kichey, T., Gerentes, D., Zivy, M., Tatout, C., et al. (2006). Two cytosolic glutamine synthetase isoforms of maize are specifically involved in the control of grain production. Plant Cell 18, 3252-3274. doi: 10.1105/tpc.106. 042689

McCartney, L., Marcus, S. E., and Knox, J. P. (2005). Monoclonal antibodies to plant cell wall xylans and arabinoxylans. J. Histochem. Cytochem. 53, 543-546. doi: 10.1369/jhc.4B6578.2005

Miflin, B. J., and Habash, D. Z. (2002). The role of glutamine synthetase and glutamate dehydrogenase in nitrogen assimilation and possibilities for improvement in the nitrogen utilization of crops. J. Exp. Bot. 53, 979-987. doi: $10.1093 /$ jexbot/53.370.979

Migge, A., Carrayol, E., Hirel, B., and Becker, T. W. (2000). Leaf-specific overexpression of plastidic glutamine synthetase stimulates the growth of transgenic tobacco seedlings. Planta 210, 252-260. doi: 10.1007/PL000 08132

Mihaljevic, S., Radic, S., Bauer, N., Garic, R., Mihaljevic, B., Horvat, G., et al. (2011). Ammonium-related metabolic changes affect somatic embryogenesis in pumpkin (Cucurbita pepo L.). J. Plant Physiol. 168, 1943-1951. doi: 10.1016/j. jplph.2011.05.025

Minocha, R., and Long, S. (2004). Simultaneous separation and quantitation of amino acids and polyamines of forest tree tissues and cell cultures within a single high-performance liquid chromatography run using dansyl derivatization. J. Chromatogr. A 1035, 63-73. doi: 10.1016/j.chroma.2004. 02.026

Molina-Rueda, J. J., and Kirby, E. G. (2015). Transgenic poplar expressing the pine GS1a show alterations in nitrogen homeostasis during drought. Plant Physiol. Biochem. 94, 181-190. doi: 10.1016/j.plaphy.2015.06.009

Moyle, R., Schrader, J., Stenberg, A., Olsson, O., Saxena, S., Sandberg, G., et al. (2002). Environmental and auxin regulation of wood formation involves members of the Aux/IAA gene family in hybrid aspen. Plant J. 31, 675-685. doi: 10.1046/j.1365-313X.2002.01386.x

Novaes, E., Kirst, M., Chiang, V., Winter-Sederoff, H., and Sederoff, R. (2010) Lignin and biomass: a negative correlation for wood formation and lignin content in trees. Plant Physiol. 154, 555-561. doi: 10.1104/pp.110.161281

Novaes, E., Osorio, L., Drost, D. R., Miles, B. L., Boaventura-Novaes, C. R. D., Benedict, C., et al. (2009). Quantitative genetic analysis of biomass and wood chemistry of Populus under different nitrogen levels. New Phytol. 182, 878-890. doi: 10.1111/j.1469-8137.2009.02785.x

Nunes-Nesi, A., Fernie, A. R., and Stitt, M. (2010). Metabolic and signaling aspects underpinning the regulation of plant carbon nitrogen interactions. Mol. Plant 3, 973-996. doi: $10.1093 / \mathrm{mp} / \mathrm{ssq} 049$ 
Oliveira, I. C., Brears, T., Knight, T. J., Clark, A., and Coruzzi, G. M. (2002). Overexpression of cytosolic glutamine synthetase. Relation to nitrogen, light, and photorespiration. Plant Physiol. 129, 1170-1180. doi: 10.1104/pp.020013

O'Neal, D., and Joy, K. W. (1973). Glutamine synthetase of pea leaves. I. Purification, stabilization, and pH optima. Arch. Biochem. Biophys. 159, 113-122. doi: 10.1016/0003-9861(73)90435-9

Ortega, J. L., Temple, S. J., and Sengupta-Gopalan, C. (2001). Constitutive overexpression of cytosolic glutamine synthetase (GS1) gene in transgenic alfalfa demonstrates that GS1 may be regulated at the level of RNA stability and protein turnover. Plant Physiol. 126, 109-121. doi: 10.1104/pp.126.1.109

Plavcova, L., Hacke, U. G., Almeida-Rodriguez, A. M., Li, E., and Douglas, C. J. (2013). Gene expression patterns underlying changes in xylem structure and function in response to increased nitrogen availability in hybrid poplar. Plant Cell Environ. 36, 186-199. doi: 10.1111/j.1365-3040.2012.02566.x

Pollmann, S., Duchting, P., and Weiler, E. W. (2009). Tryptophan-dependent indole-3-acetic acid biosynthesis by 'IAA-synthase' proceeds via indole-3acetamide. Phytochemistry 70, 523-531. doi: 10.1016/j.phytochem.2009.01.021

Qiu, Z., Wang, L., and Zhou, Q. (2013). Effects of bisphenol A on growth, photosynthesis and chlorophyll fluorescence in above-ground organs of soybean seedlings. Chemosphere 90, 1274-1280. doi: 10.1016/j.chemosphere. 2012.09.085

Raes, J., Rohde, A., Christensen, J. H., Van De Peer, Y., and Boerjan, W. (2003). Genome-wide characterization of the lignification toolbox in Arabidopsis. Plant Physiol. 133, 1051-1071. doi: 10.1104/pp.103.026484

Rennenberg, H., Wildhagen, H., and Ehlting, B. (2010). Nitrogen nutrition of poplar trees. Plant Biol. 12, 275-291. doi: 10.1111/j.1438-8677.2009.00309.x

Seger, M., Gebril, S., Tabilona, J., Peel, A., and Sengupta-Gopalan, C. (2015). Impact of concurrent overexpression of cytosolic glutamine synthetase (GS1) and sucrose phosphate synthase (SPS) on growth and development in transgenic tobacco. Planta 241, 69-81. doi: 10.1007/s00425-014-2165-4

Seger, M., Ortega, J. L., Bagga, S., and Gopalan, C. S. (2009). Repercussion of mesophyll-specific overexpression of a soybean cytosolic glutamine synthetase gene in alfalfa (Medicago sativa L.) and tobacco (Nicotiana tabacum L.). Plant Sci. 176, 119-129. doi: 10.1016/j.plantsci.2008.10.006

Stepanova, A. N., Hoyt, J. M., Hamilton, A. A., and Alonso, J. M. (2005). A link between ethylene and auxin uncovered by the characterization of two rootspecific ethylene-insensitive mutants in Arabidopsis. Plant Cell 17, 2230-2242. doi: 10.1105/tpc.105.033365

Stepanova, A. N., Robertson-Hoyt, J., Yun, J., Benavente, L. M., Xie, D. Y., Dolezal, K., et al. (2008). TAA1-mediated auxin biosynthesis is essential for hormone crosstalk and plant development. Cell 133, 177-191. doi: 10.1016/j. cell.2008.01.047

Suarez, R., Marquez, J., Shishkova, S., and Hernandez, G. (2003). Overexpression of alfalfa cytosolic glutamine synthetase in nodules and flowers of transgenic Lotus japonicus plants. Physiol. Plant. 117, 326-336. doi: 10.1034/j.1399-3054. 2003.00053.X

Sun, J. Q., Xu, Y. X., Ye, S. Q., Jiang, H. L., Chen, Q., Liu, F., et al. (2009). Arabidopsis ASA1 is important for jasmonate-mediated regulation of auxin biosynthesis and transport during lateral root formation. Plant Cell 21, 1495-1511. doi: $10.1105 /$ tpc. 108.064303
Tabuchi, M., Abiko, T., and Yamaya, T. (2007). Assimilation of ammonium ions and reutilization of nitrogen in rice (Oryza sativa L.). J. Exp. Bot. 58, 2319-2327. doi: $10.1093 / \mathrm{jxb} / \mathrm{erm} 016$

Tobin, A. K., and Yamaya, T. (2001). Cellular compartmentation of ammonium assimilation in rice and barley. J. Exp. Bot. 52, 591-604. doi: 10.1093/jexbot/52. 356.591

Vincent, R., Fraisier, V., Chaillou, S., Limami, M. A., Deleens, E., Phillipson, B., et al. (1997). Overexpression of a soybean gene encoding cytosolic glutamine synthetase in shoots of transgenic Lotus corniculatus L. plants triggers changes in ammonium assimilation and plant development. Planta 201, 424-433. doi: $10.1007 / \mathrm{s} 004250050085$

Voelker, S. L., Lachenbruch, B., Meinzer, F. C., and Strauss, S. H. (2011). Reduced wood stiffness and strength, and altered stem form, in young antisense 4CL transgenic poplars with reduced lignin contents. New Phytol. 189, 1096-1109. doi: 10.1111/j.1469-8137.2010.03572.x

Wang, X. C., Wei, Y. H., Shi, L. X., Ma, X. M., and Theg, S. M. (2015). New isoforms and assembly of glutamine synthetase in the leaf of wheat (Triticum aestivum L.). J. Exp. Bot. 66, 6827-6834. doi: 10.1093/jxb/erv388

Wei, Z., Qu, Z., Zhang, L., Zhao, S., Bi, Z., Ji, X., et al. (2015). Overexpression of poplar xylem sucrose synthase in tobacco leads to a thickened cell wall and increased height. PLOS ONE 10:e0120669. doi: 10.1371/journal.pone.01 20669

Welker, C., Balasubramanian, V., Petti, C., Rai, K., Debolt, S., and Mendu, V. (2015). Engineering plant biomass lignin content and composition for biofuels and bioproducts. Energies 8, 7654-7676. doi: 10.1186/s13068-0160445-X

Wu, A. M., Hornblad, E., Voxeur, A., Gerber, L., Rihouey, C., Lerouge, P., et al. (2010). Analysis of the Arabidopsis IRX9/IRX9- L and IRX14/IRX14- L pairs of glycosyltransferase genes reveals critical contributions to biosynthesis of the hemicellulose glucuronoxylan. Plant Physiol. 153, 542-554. doi: 10.1104/pp. 110.154971

Zhao, Y. (2010). Auxin biosynthesis and its role in plant development. Annu. Rev. Plant Biol. 61, 49-64. doi: 10.1146/annurev-arplant-042809-11 2308

Zhu, C., Fan, Q., Wang, W., Shen, C., Wang, P., Meng, X., et al. (2014). Characterization of a glutamine synthetase gene DvGS1 from Dunaliella viridis and investigation of the impact on expression of DvGS1 in transgenic Arabidopsis thaliana. Mol. Biol. Rep. 41, 477-487. doi: 10.1007/s11033-0132882-y

Conflict of Interest Statement: The authors declare that the research was conducted in the absence of any commercial or financial relationships that could be construed as a potential conflict of interest.

Copyright (c) $2018 \mathrm{Lu}, \mathrm{Liu}, \mathrm{Wei}, \mathrm{Liu}, \mathrm{Qu}$, Yang, Wei and Wei. This is an open-access article distributed under the terms of the Creative Commons Attribution License (CC BY). The use, distribution or reproduction in other forums is permitted, provided the original author(s) or licensor are credited and that the original publication in this journal is cited, in accordance with accepted academic practice. No use, distribution or reproduction is permitted which does not comply with these terms. 